\section{Historical American Documents}

A NUMBER of studies of historical documents in the library of the American Philosophical Society is contained in a recent publication (Proc. Amer. Phil. Soc., 100, No. $6 ; 1956$ ). It includes one by Whitfield J. Bell, jun., entitled "All Clear Sunshine", describing some unpublished correspondence between Benjamin Franklin and Mary Stevenson Hewson, acquired by the Society by gift and purchase in March 1956. About half these letters are addressed to Franklin and they will be published in the forthcoming edition of "The Papers of Benjamin Franklin", sponsored by the Society and Yale University. A second study, by I. B. Cohen, discusses some problems in relation to the dates of Benjamin Franklin's first letters on electricity. Prof. T. D. Cope describes the running of a meridian line northward up the Delmarva peninsula beginning on December 11, 1760, and continuing with interruptions from the weather until it was completed on November 2, 1761.

\section{The Chemical Society}

THE following are those holding office in the Chemical Society, including those recently elected to office: President, Prof. E. L. Hirst ; Vice-Presidents who have filled the office of President, Sir Ian Heilbron, Sir Cyril Hinshelwood, Prof. C. K. Ingold, Dr. W. H. Mills, Sir Eric Rideal and Prof. W. Wardlaw; Vice-Presidents, Prof. Wilson Baker, Prof. R. D. Haworth, Prof. E. D. Hughes, Prof. M. Stacey, Dr. L. E. Sutton and Sir Alexander Todd; Honorary Treasurer, M. W. Perrin ; Honorary Secretaries, Prof. F. Bergel, Dr. J. Chatt and Prof. M. J. S. Dewar.

\section{Radioisotopes in Scientific Research}

AN International Conference on Radioisotopes in Scientific Research has been convened by Unesco and will be held in Paris during September 9-20. Participants will include those nominated by govern. ments ; representatives of the United Nations or its specialized agencies ; representatives of international scientific organizations; and persons participating in an individual capacity, or on behalf of scientific or industrial bodies. The purpose of the Conference, which will be strictly scientific in character, will be the exposition and discussion of new ideas or methods for the utilization of radioisotopes in scientific research. Plenary sessions are to be devoted to new developments in measuring techniques and significant developments in the production of radioisotopes. The remainder of the work of the Conference will take place in two main sections, dealing with the physical and biological sciences. Further details can be obtained from the United Kingdom National Commission for Unesco, Ministry of Education, Curzon Street, London, W.1. Participants are asked to submit titles and 250 -word summaries of their papers by May 1, and the complete texts of the papers by July 1. Proceedings of the Conference will be published by Unesco in due course.

\section{The Union Observatory, Johannesburg, 1953-55}

THe Annual Reports of the Union Observatory, Johannesburg, for each of the three years 1953-55 follow similar lines, and it will be sufficient to notice outstanding events during the period. The $26 \frac{1}{2}$-in. refractor was used with the interferometer by Dr. W. S. Finsen for the measurement of known double stars and a search for new pairs, and Dr. W. H. van den Bos and Mr. J. Churms have also taken part in the first portion of that programme. With the Franklin-Adams telescope, plates were obtained by Messrs. E. L. Johnson, J. A. Bruwer and J. Churms of minor planets, comets, variable stars and a 'miscellaneous' collection : as this telescope was badly handicapped by increasing city lights and smoke, it was dismantled in August 1954 and transferred to the Observatory Annexe at Hartbeespoort, where, as is pointed out in the Report for 1955 , it continued with this work with the advantage of a dark night sky. With the 9 -in. and 6-in. refractors, occultations of stars by the Moon were observed by. Bruwer and Churms, and in addition, by amateur astronomers who are members of the Astronomical Society of South Africa (Transvaal Branch); the latter also used the 9-in. refractor for the observations of planets and variable stars, and rendered valuable assistance to the staff on visiting evenings. In 1953, the occultation of Antares and its companion on March 7 was successfully recorded photoelectrically by $a_{\text {t team }}$ of observers who used the Leyden telescope, and in the same year the transit of Mercury on November 14 was observed with three telescopes by Messrs. Finsen, Bruwer, P. C. Seligmann and J. Churms.

With the 3-in. refractor counts of sunspots were made, and results were obtained on 288, 308 and 265 days, respectively, in each of the years under consideration. The results were communicated daily to the Telecommunications Research Laboratory of the South African Council for Scientific and Industrial Research, and monthly to the Magnetic Observatory at Hermanus and the Receiving Station of the South African Broadcasting Corporation at Panorama. Other matters dealt with are publications, public services and staff; the second of these includes the time service, which is under the general supervision of Dr. Finsen with Mr. J. Hers in charge, assisted by Messrs. Seligmann, Bruwer and Churms. One interesting matter may be mentioned in conclusion: on April 1, 1953, the Observatory celebrated its golden jubilee by holding an open day, and about 4,000 visitors were conducted over the buildings.

\section{The Night Sky in May}

FuLL Moon occurs on May 13d. 22h. 34m. U.T., and new Moon on May 29d. 11h. 39m. The following conjunctions with the Moon take place: May 3d. 18h., Mars $5^{\circ}$ N. ; May 9d. 19h., Jupiter $6^{\circ}$ N.; May 15d. 09h., Saturn $0.2^{\circ} \mathrm{S}$. In addition to these conjunctions with the Moon, Venus is in conjunction with Aldebaran on May 21d. 15h., Venus being $5.7^{\circ}$ $N$. There will be a total eclipse of the Moon on May 13-14, visible at Greenwich. The Moon enters penumbra at $19 \mathrm{~h} .42 \mathrm{~m}$. and umbra at $20 \mathrm{~h}$. $45 \mathrm{~m}$.; totality begins at $21 \mathrm{~h} .52 \mathrm{~m}$. and ends at $23 \mathrm{~h} .10 \mathrm{~m}$.; the Moon leaves umbra at $00 \mathrm{~h} .17 \mathrm{~m}$. and penumbra at $01 \mathrm{~h}$. 20m. Mercury is too close to the Sun for normal observation. Inferior conjunction occurs on May 6 , and on that date there will be a transit of Mercury across the Sun's disk. 'This rare phenomenon will unfortunately be invisible at Greenwich. Venus is now an ovening star, but is still too close to the Sun for easy observation, setting about an hour after the Sun at the end of the month. Mars sets at $23 \mathrm{~h}$. $35 \mathrm{~m}$., $23 \mathrm{~h} .20 \mathrm{~m}$. and $22 \mathrm{~h}$. $50 \mathrm{~m}$. on May 1,15 and 31 , respectively; its stellar magnitude is about $+1 \cdot 9$, and its distance in the middle of the month is 208 million miles. Mars enters Gemini on May 3, and is near $\delta$ Geminorum at the end of the month. Jupiter sets at $3 \mathrm{~h}$. $20 \mathrm{~m} ., 2 \mathrm{~h} .20 \mathrm{~m}$. and $\mathrm{Ih} .20 \mathrm{~m}$. at the 